\title{
Improvement of sheep skin quality after treatment with diazinon against cockle
}

\author{
Kassa Bayou ${ }^{1}$, Biruk Alemu ${ }^{2}$, Yeshimebet Chanyalew ${ }^{2}$, and Demeke Tumsa ${ }^{3}$ Solomon \\ Gizaw $^{2}$ \\ ${ }^{1}$ Former Animal Health Program Coordinator for USAID-ATEP, P. O. Box 62505, Addis Ababa. \\ ${ }^{2}$ Debre Birhan Agriculture Research Centre, P. O. Box 112, Debre Birhan. \\ ${ }^{3}$ Ethiopia Tannery, P. O. Box 5628, Addis Ababa
}

\begin{abstract}
Cockle, otherwise known as ekek locally, has been economically the most important skin defect among the tanneries in Ethiopia for the last three decades. The disease has been experimented on since 1996 when FAO sponsored the trials on sheep and goat skin improvement trial (TCP/ETH/4558\&6712) and found that diazinon improved the skin quality of treated sheep at least by 1 grade. However, the trials had not been sustainable to find out what the skin quality of the lambs of the dams that had been treated with diazinon would look like. The trial carried out at Debre Birhan Agriculture Research Centre filled this gap and showed repeatedly that sheep treated against lice and keds with diazinon improved the skin quality of the adult by 1 grade and those of their lambs by 3-5 grades. It started with $367 \mathrm{Menz}$ and 265 Horro sheep in October 2009 and completed in January 2011. Lice and keds count of the trial sheep was carried out before and after treatment with diazinon. After the treatment, the parasite count dropped to 0 and there was a significant difference between the skin grades of the sheep before and after treatment with diazinon at $95 \%$ confidence level. The dramatic skin quality improvement appeared in the lambs which, compared to the adult sheep skins, had improved by $89 \%$ to $90 \%$.
\end{abstract}

Keywords: Cockle, Diazinon, Ethiopia, Horro and Menz sheep, Skin quality improvement.

http://dx.doi.org/10.4314/evj.v16i2.5

\section{Introduction.}

Tannery owners in Ethiopia complained that, three decades ago, they used to get the best quality sheep skins over $70 \%$ of what they produce today, but due to the cockle problem, today it has dwindled to $15 \%$. Cockle is an allergic reaction caused by the faeces and saliva of lice and keds. It is manifested as 
small nodules of 0.5 to $1 \mathrm{~mm}$ in diameter or as greyish or brownish discoloration on the dermis of the skin which is apparent only when the skin is flayed and processed in the tannery.

Cockle, causes rejection or down grading in more than $50 \%$ of processed skins in tanneries. The best skins that could be sold as grade 1-3 at USD $80-100 /$ dozen if they had no cockle, would be sold for less than USD 15/dozen when graded as rejects due to cockle. Skins of grade 4 cost USD 64/dozen and skins of grade 5 cost USD 25 /dozen (Kassa, 2009). This skin disease was first identified and associated with the sheep louse Bovicola ovis (Formerly known as Damalinia ovis) by Heath et al in 1995 in New Zealand sheep. The presence of the disease was confirmed in Ethiopia in an FAO project in 1996-98(TCP/ETH/4558\&6712). The Project also identified diazinon to be a cost effective drug that eliminated the parasites and controlled cockle, although other insecticides like amitraz, deltamethrine and coumaphos were also available in the country which were more expensive than diazinon.

A number of trials that demonstrated the effect of diazinon on ectoparasites that cause cockle and the defect itself have been carried out locally as well as in other countries. However, some tannery owners were sceptical about the effect of diazinon in controlling the diseases. The scepticism arose as a result of the inconsistency of treatments given so far which did not bring about change in the problem, although a lot of publicity was given about them. This project, therefore, helps

- to demonstrate the effect of diazinon treatment on both the parasites that cause cockle and the skin quality, so that tanneries would not doubt of its efficacy and be part of the national campaign to control the disease using diazinon.

- to compare the skin quality of the Menz breed and that of the Horro Breed with regard to resistance to cockle.

- to demonstrate that parasite free sheep from birth will have no cockle defect when compared to sheep that had the parasites once and got rid of it later.

\section{Materials and Methods}

\section{Study area/location}

The sheep flock were maintained at Debre Birhan Agricultural Research Centre located in central Ethiopia at $120 \mathrm{~km}$ north-east of Addis Ababa at 
latitude $9^{\circ} 36^{\prime} \mathrm{N}$ and longitude $39^{\circ} 38^{\prime} \mathrm{E}$. It is located at an altitude of 2850 $\mathrm{m}$ above sea level with a bimodal rainfall pattern consisting of a long rainy season which is extended from June to September and a short rainy season from March to May. The mean annual rainfall, mean temperature (ranging from an average minimum of $6.3^{\circ} \mathrm{C}$ to an average maximum of $18.8^{\circ} \mathrm{C}$ ) and mean relative humidity were $956 \mathrm{~mm}, 12.6^{\circ} \mathrm{C}$ and $59.6 \%$ respectively for the period 1979-1989. Debre Birhan is a mixed farming area known for sheep production.

\section{Study animal}

A flock of $599 \mathrm{Menz}$ and 265 Horro breed sheep were used for the study which extended from October 2009 to January 2011. Among the Menz sheep 413 were male and 186 female which were bought from Debre Birhan, Sela Dingay and Tarma Ber, all of which were found within the North Shoa Zone of the Amhara Region. The reason behind purchasing the Menz sheep breed was because of the poor skin quality branded to the Menz sheep in North Shoa region by the tanneries in Ethiopia because of the cockle skin defects. The Menz breed type is one of the few African wool-bearing sheep which is indigenous to the study area. It is concentrated in the central highlands between 2500 and $3000 \mathrm{~m}$ above sea level. It is a fat-tailed breed of relatively small size (mature ewes range from 25 to $35 \mathrm{~kg}$ ).

The Horro sheep breed comprising, 178 ewes and 86 rams, were bought from their traditional habitat in western Ethiopia in Ambo area and were quarantined for 2 weeks before joining the experiment in April 2010. This sheep breed is found at an altitude of 1400- 2000 m.a.s.l with a dependable annual rainfall averaging $1000-1400 \mathrm{~mm}$. It is a fat-tailed hair breed. Coat colours are mostly uniformly brown or light brown (83\%); few of the sheep (10\%) have white with brown, plain white (3\%) or plain black (2\%) colours (Tibbo et al., 2004b). They are larger sheep than the Menz, with mature ewes ranging from 35 to $45 \mathrm{~kg}$ (Galal, 1983).

\section{Flock management}

For the duration of the study, the animals were grouped by breed and each breed was grouped by sex except for some rams that joined the ewes for breeding purpose. Each group was housed in separate pen with concrete floor and each animal was identified with an ear tag number. 
The Menz and Horro sheep were grazed separately. Apart from grazing the natural pasture during day time, all sheep were also provided with hay in the evening and were supplemented with concentrates at $300 \mathrm{~g} /$ day and watered twice a day.

They were also vaccinated against sheep pox, PPR and pasteurellosis and treated against nematodes and trematodes in June, September and January. Routine health monitoring was undertaken every morning and those that had problems were treated with antibiotic and/or antihelimentics as deemed necessary. Both flocks had clinical records to record their health problem and mortality and they had body weight measurement every month.

\section{Parasite count and treatment with diazinon}

Lice and keds count were taken on the predilection sites i.e. the neck, shoulder, back, belly, flank, and rump, before and two weeks after treatment with diazinon to confirm the efficacy of the treatment. Treatment with diazinon $(0.06 \%)$ had taken place one month after introduction of the Horro breed, twice at two weeks interval by handling the animals one by one and every three month thereafter. One $\mathrm{ml}$ of $60 \%$ of the concentrated solution was diluted in 1 litre of tap water to make $0.06 \%$ solution that looked milky after the mixture. This was sprayed on the whole body of each of the sheep using knap sack sprayers

\section{Skin quality assessment}

The skins received from the three slaughters were graded at pickled stage. The selectors were instructed to grade the skins based on the cockle defects only, without considering defects like flay cuts, sheep pox or putrefaction.

During the first Round slaughter no lambs were included, because by then the lambs were too small in age to slaughter. During the second Round, only 13 lambs were available to slaughter and during the third Round there were twenty lambs from each breed. Therefore, during the second slaughter although 400 sheep were slaughtered, twelve skins were selected randomly from both the adult Menz and the adult Horro sheep. And during the third Round only 20 adult sheep were slaughtered from each breed to match the number of lambs available from each breed. During processing the skins in the tannery, two skins were missing recovering 37 skins in total.

Before treatment with diazinon started, 10 sheep from each breed were slaughtered to determine the quality of the sheep skins before treatment as 
a bench mark. The skins were then preserved with salt and taken to Ethiopia Tannery for processing. They were then processed to the pickled and crust stages. Their body wt and carcass wt and dressing percentage of both breeds was also taken.

\section{Body weight, carcass weight and dressing percentage.}

The body weight of sheep was taken in the morning as soon as they went out of their pens before they were grazed. This was taken using a weigh bridge. The carcass weight was taken by giving a code number to the carcass which corresponded to the ear tag. The first slaughter was taken at the premises of Ethiopia Tannery while the second and third slaughter was taken at Luna abattoir.

\section{Statistical analysis methods}

The variables to be analyzed were skin grades between breeds and age groups. STATA was used for analysis of variance (ANOVA) and SPSS version were used to detect significant differences between and within subject effects and to correlate associated factors to the breeds and ages involved in the study.

\section{Results}

\section{Lice and keds infestation}

The Menz adult sheep slaughtered during the first Round had 91 lice and 1.2 keds/sheep. The Horro had 95.4 lice but no sheep ked. (Table 1)

Before treatment, the Menz adult sheep, slaughtered during $2^{\text {nd }}$ Round, had 43.08 lice and 2 keds/sheep and the Horro had only lice, 104.5/sheep, and no keds. Among the lambs, one had lice which counted 108. No other lamb was infested with either lice or keds. (Table 2). After treatment they were all negative for lice and keds.

Table 1. Ectoparasite infestation of sheep slaughtered during the 1st Round

\begin{tabular}{llccccc}
\hline & \multicolumn{2}{c}{ Menz adult sheep. $(\mathrm{N}=10)$} & \multicolumn{2}{c}{ Horro adult sheep $(\mathrm{N}=10)$} \\
\cline { 2 - 7 } & \multicolumn{2}{c}{ Lice } & Keds & Lice & Keds \\
\hline Total & 910 & 12 & 954 & 0 & \\
Average & 91 & 1.2 & 95.4 & 0 & \\
\hline
\end{tabular}


Table 2. Lice and keds count of 2 nd Round slaughtered sheep before and after treatment with diazinon

\begin{tabular}{|c|c|c|c|c|c|c|c|c|c|c|c|}
\hline \multicolumn{4}{|c|}{ Menz sheep $(\mathrm{N}=12)$} & \multicolumn{4}{|c|}{ Horro sheep $(\mathrm{N}=12)$} & \multicolumn{4}{|c|}{ Menz\&Horro lambs(N=13) } \\
\hline \multicolumn{2}{|c|}{$\begin{array}{c}\text { Before } \\
\text { Treatment }\end{array}$} & \multicolumn{2}{|c|}{$\begin{array}{c}\text { After } \\
\text { Treatment }\end{array}$} & \multicolumn{2}{|c|}{$\begin{array}{c}\text { Before } \\
\text { Treatment }\end{array}$} & \multicolumn{2}{|c|}{$\begin{array}{c}\text { After } \\
\text { Treatment }\end{array}$} & \multicolumn{2}{|c|}{$\begin{array}{c}\text { Before } \\
\text { Treatment }\end{array}$} & \multicolumn{2}{|c|}{$\begin{array}{c}\text { After } \\
\text { Treatment }\end{array}$} \\
\hline lice & keds & lice & keds & lice & keds & lice & keds & lice & keds & lice & keds \\
\hline 517 & 24 & 0 & 0 & 1254 & 0 & 0 & 0 & 108 & 0 & 0 & 0 \\
\hline 43.08 & 2 & 0 & 0 & 104.5 & 0 & 0 & 0 & 9 & 0 & 0 & 0 \\
\hline
\end{tabular}

Before treatment, the Menz adult sheep slaughtered during the $3^{\text {rd }}$ Round had 46.1 lice and $1.7 \mathrm{keds} / \mathrm{sheep}$, while the Horro had 50.2 lice and 0.5keds/sheep. After treatment all the adult sheep were negative for ectoparasites. But none of the lambs had ectoparasite infestation even before the treatment.(Table 3)

Table 3. Lice and keds count of 3rd Round slaughtered sheep before and after treatment with diazinon

\begin{tabular}{|c|c|c|c|c|c|c|c|c|c|c|c|c|c|c|c|c|}
\hline & \multicolumn{4}{|c|}{$\begin{array}{c}\text { Menz adult } \\
\text { sheep }(\mathrm{N}=20)\end{array}$} & \multicolumn{4}{|c|}{$\begin{array}{l}\text { Horro Adult } \\
\text { Sheep }(\mathrm{N}=20)\end{array}$} & \multicolumn{4}{|c|}{$\begin{array}{c}\text { Menz lambs } \\
(\mathrm{N}=19)\end{array}$} & \multicolumn{4}{|c|}{$\begin{array}{l}\text { Horro lambs } \\
(\mathrm{N}=19)\end{array}$} \\
\hline & \multicolumn{2}{|c|}{$\begin{array}{c}\text { Before } \\
\text { treament }\end{array}$} & \multicolumn{2}{|c|}{$\begin{array}{c}\text { After } \\
\text { treatment }\end{array}$} & \multicolumn{2}{|c|}{$\begin{array}{c}\text { Before } \\
\text { treament }\end{array}$} & \multicolumn{2}{|c|}{$\begin{array}{c}\text { After } \\
\text { treatment }\end{array}$} & \multicolumn{2}{|c|}{$\begin{array}{c}\text { Before } \\
\text { treament }\end{array}$} & \multicolumn{2}{|c|}{$\begin{array}{c}\text { After } \\
\text { treatment }\end{array}$} & \multicolumn{2}{|c|}{$\begin{array}{c}\text { Before } \\
\text { treament }\end{array}$} & \multicolumn{2}{|c|}{$\begin{array}{c}\text { After } \\
\text { treatment }\end{array}$} \\
\hline & lice & keds & lice & keds & lice & keds & lice & keds & lice & keds & lice & keds & lice & keds & lice & keds \\
\hline Total & 922 & 34 & 0 & 0 & 1004 & 2 & 0 & 0 & 0 & 0 & 0 & 0 & 0 & 0 & 0 & 0 \\
\hline Average & 46.1 & 1.7 & 0 & 0 & 50.2 & 0.05 & 0 & 0 & 0 & 0 & 0 & 0 & 0 & 0 & 0 & 0 \\
\hline
\end{tabular}

\section{Skin Grades}

The skin grades out of the ten Menz sheep skins processed during the first Round, $50 \%$ were in $5^{\text {th }}$ grade, $10 \%$ in grade RA and $40 \%$ in RB. Out of the ten Horro sheep skins processed, $20 \%$ were in $3^{\text {rd }}$ grade, $20 \%$ in 4 th and $60 \%$ in $5^{\text {th }}$. (Table 4) 
Table 4. Skin grades of the diazinon trial sheep slaughtered in three Rounds

\begin{tabular}{lllllllll}
\hline Slaughter & \multirow{2}{*}{ Bound } & Breed and age & \multicolumn{9}{l}{ Skin grades (\%) } \\
\cline { 3 - 9 } & & 1st & 2nd & 3rd & 4th & 5th & RA & RB \\
\hline 1st Round & Menz adult & - & - & - & - & 50 & 10 & 40 \\
& Horro adult & - & - & 20 & 20 & 60 & & \\
\multirow{5}{*}{ 2nd Round } & Menz adult & - & - & 8.33 & - & 25 & 66.67 & \\
& Horro adult & - & - & - & 33.33 & 58.33 & 8.33 & \\
& Menz \& Horro & 33.33 & 41.67 & 16.67 & 8.33 & & & \\
& lambs & & & & & & & \\
3rd Round & Menz adult & - & - & 5 & 5 & 60 & 30 & \\
& Horro adult & - & 5 & 10 & 20 & 60 & 5 & \\
& Menz \& Horro & 38.46 & 33.33 & 17.95 & 10.26 & & & \\
& lambs & & & & & & & \\
\hline
\end{tabular}

During the $2^{\text {nd }}$ slaughter, among the adult Menz sheep skins $8.33 \%$ of the skins were graded as $3^{\text {rd }}, 25 \%$ as $5^{\text {th }}$ and $66.67 \%$ as RA. The Horro adult skins had $33.33 \%$ of the skins in the $4^{\text {th }}$ grade, $58.33 \%$ in $5^{\text {th }}$ grade and $8.33 \%$ in RA grade. Out of the 13 lamb skins processed, $91.67 \%$ were in the best skin grades (grade $1-3$ ). And only $8.33 \%$ of the skins were in the $4^{\text {th }}$ grade.

During the $3^{\text {rd }}$ Round slaughter, the Menz sheep had 5\% in $3^{\text {rd }}$ grade, $5 \%$ in $4^{\text {th }}$ grade, $60 \%$ in $5^{\text {th }}$ grade and only $30 \%$ were rejects. Among the adult Horro sheep, $5 \%$ were in $2^{\text {nd }}$ grade $10 \%$ were in $3^{\text {rd }}$ grade, $20 \%$ in $4^{\text {th }}$ grade and $60 \%$ in $5^{\text {th }}$ grade and $5 \%$ in RA. Out of the 20 lamb skins, $90 \%$ had the best grades and only $10 \%$ were in $4^{\text {th }}$ grade.

Table 5. skin grades of Menz and Horro lambs

\begin{tabular}{lcc}
\hline Grade & Menz lambs & Horro lambs \\
\hline 1st grade & $42.11 \%$ & $35 \%$ \\
2nd grade & $26.32 \%$ & $40 \%$ \\
3rd grade & $21.05 \%$ & $15 \%$ \\
4th grade & $10.52 \%$ & $10 \%$ \\
5 th grade & 0 & 0 \\
Reject RA & 0 & 0 \\
Reject RB & 0 & 0 \\
Reject RC & 0 & 0 \\
Total skins & 19 & 20 \\
\hline
\end{tabular}




\section{Body wt., carcass wt. and dressing percentage}

Body weight and carcass weight of the two breeds show that, during the first slaughter, the Menz adult sheep had body wt. Increase of $4.6 \mathrm{~kg}$ and carcass wt. of $7.8 \mathrm{~kg}$., while the Horro had $1.1 \mathrm{~kg}$ and $10 \mathrm{~kg}$ respectively. During the second slaughter the Menz sheep had body wt. increase of $10.29 \mathrm{~kg}$ and carcass wt. of $10 \mathrm{~kg}$, while the Horro had 6.25 and $11.8 \mathrm{~kg}$ respectively. During the third slaughter the Menz had $9.98 \mathrm{~kg}$ and $13.7 \mathrm{Kg}$. respectively. (Table 6)

The lambs slaughtered during the $2^{\text {nd }}$ slaughter were mostly Menz lambs (12:1). Therefore, the body wt. and carcass wt. of the lambs slaughtered during the $2^{\text {nd }}$ slaughter was not considered for comparison.

During the $3^{\text {rd }}$ slaughter, the Menz lambs had an increase in body wt. of $9.75 \mathrm{~kg}$ and carcass wt. of $5.27 \mathrm{~kg}$ while the Horro had $5.95 \mathrm{~kg}$ and $5.23 \mathrm{~kg}$ respectively.

During the $1^{\text {st }}$ slaughter, the dressing percentage of the Menz adult sheep was 39.6 while that of the Horro was 41 . During the $2^{\text {nd }}$ slaughter the dressing percentage of the Menz adult sheep was 42.57 and that of Horro was 40.9. During the $3^{\text {rd }}$ slaughter the dressing percentage of the Menz adult sheep was 38.31 and that of Horro was 40.76

During the $3^{\text {rd }}$ slaughter, the dressing percentage of both Menz and Horro lambs was similar which was 34.85 . 
Table 6. Slaughter record of the trial sheep in Debre Birhan Agriculture Research Center

\begin{tabular}{|c|c|c|c|c|c|c|c|}
\hline $\begin{array}{l}\text { Slaughter } \\
\text { Round } \\
\end{array}$ & Breed & $\begin{array}{l}\text { Total/ } \\
\text { Avg. }\end{array}$ & $\begin{array}{l}\text { Initial } \\
\text { Bd.wt(kg) }\end{array}$ & $\begin{array}{l}\text { Final } \\
\text { bd.wt(kg) }\end{array}$ & $\begin{array}{l}\text { Bd.wt. } \\
\text { diff. }\end{array}$ & $\begin{array}{l}\text { Carcass } \\
\text { wt. (kg) }\end{array}$ & $\begin{array}{l}\text { Dressing } \\
\%\end{array}$ \\
\hline 1st Round & $\begin{array}{l}\text { Menz } \\
\text { adult(N=10) }\end{array}$ & Total & 150.45 & 196.5 & 46.05 & 78 & 396.13 \\
\hline \multirow[t]{3}{*}{ 02/05/2010 } & & Average & 15.05 & 19.65 & 4.6 & 7.8 & 39.6 \\
\hline & Horro & Total & 241 & 247 & 11 & 101 & 410.21 \\
\hline & & Average & 2.4 & 2.47 & 1.1 & 10.1 & 41.02 \\
\hline 2nd Round & $\begin{array}{l}\text { Menz } \\
\text { adult }(\mathrm{N}=12)\end{array}$ & Total & 178 & 301.5 & 123.5 & 126.9 & 510.85 \\
\hline \multirow[t]{7}{*}{ 02/10/2010 } & & Average & 14.83 & 25.13 & 10.29 & 10.58 & 42.57 \\
\hline & Horro & Total & 271.5 & 346.5 & 75 & 141.7 & 490.92 \\
\hline & Adult(N=12) & & & & & & \\
\hline & & Average & 22.6 & 28.87 & 6.25 & 11.81 & 40.91 \\
\hline & $\begin{array}{l}\text { Menz \& } \\
\text { Horro }\end{array}$ & Total & 43.95 & 152.5 & 108.6 & 58.1 & 495.12 \\
\hline & $\operatorname{lambs}(\mathrm{N}=13)$ & & & & & & \\
\hline & & Average & 3.38 & 11.73 & 8.35 & 4.84 & 41.26 \\
\hline 3rd Round & $\begin{array}{l}\text { Menz } \\
\text { adult( }(\mathrm{N}=12)\end{array}$ & Total & 297.8 & 585 & 287.2 & 226 & 766.1 \\
\hline \multirow[t]{8}{*}{$19 / 01 / 2011$} & & Average & 14.89 & 29.25 & 14.36 & 11.3 & 38.31 \\
\hline & Horro & Total & 471.5 & 671 & 199.5 & 274 & 815.2 \\
\hline & Adult(N=12) & & & & & & \\
\hline & & Average & 23.58 & 33.55 & 9.98 & 13.7 & 40.76 \\
\hline & $\begin{array}{l}\text { Menz } \\
\operatorname{lambs}(\mathrm{N}=20)\end{array}$ & Total & 111 & 314 & 195 & 105.4 & 697 \\
\hline & & Average & 5.55 & 15.7 & 9.75 & 5.27 & 34.85 \\
\hline & $\begin{array}{l}\text { Horro } \\
\text { Lambs }(\mathrm{N}=19)\end{array}$ & Total & 193.86 & 275 & 112.5 & 99.3 & 690 \\
\hline & & Average & 10.2 & 14.47 & 5.95 & 5.23 & 34.85 \\
\hline
\end{tabular}




\section{Discussion}

The relationship between lice and keds and cockle and the effect of treatment on cockle were long established (Heath et al $(1995,1996)$, Leach \& Bayou (1998), Tsertse \& Abebe $(2006,2007)$. However, the effect of treatment on lambs during and after weaning has not been explored. This trial, therefore, elucidated this fact by treating the lambs right from the time they were suckling their dams till after weaning.

The sheep slaughtered during the $1^{\text {st }}$ Round were never treated with any insecticide before they were slaughtered. But the sheep slaughtered on the $2^{\text {nd }}$ and $3^{\text {rd }}$ Rounds were treated with diazinon. Two week after treatment they were all free of the parasites completely. Not only the adult sheep but also the lambs were all free of the parasites because of contact treatment before they were treated with the insecticide. Leach (1998) and Heath (1996) mentioned that sheep treated with diazinon can be free of the parasites for as many as 90 and 67 days respectively.

There is a significant difference between the skin grades of the Menz sheep in Round 1 and Round 3 at 95\% confidence level because of the treatment with diazinon. There is also a very significant difference between the adult Menz sheep skin grades in Round 1 and those of the Menz lambs in Round 3 because of the treatment.

There is no significant difference between the skin grades of the adult Menz sheep in Round 1 and Round 2. Although there is difference in the grades between the two groups as seen in the table, statistically it was not significant because the difference was small.

Among the Horro sheep skin grades also, there is a significant difference between the skin grades of the Horro adult sheep in Round 1 and those of the lambs in Round 3 because of the diazinon treatment. However, statistically the difference in skin grades of the Horro adult sheep in Rounds 1, 2 and 3 are not that significant, although there is certainly a difference when one looks at the table.

There are differences between skin grades in the 1st, 2nd,and 3rd Rounds between the Menz adult and Horro adult sheep. This is because the Horro sheep were not exposed to sheep ked infestation so much as were the Menz sheep because of the hair size which was short to harbour the keds. 
The reason behind the improvement of the skin quality of the sheep in both the second and the third group was because of the treatment with the insecticide that killed all the lice and keds that caused cockle defect. Therefore, as predicted in the project proposal, there was an improvement of at least 1 grade in the adult sheep skins.

The major improvement in skin quality was noticed when the adult skins were compared with those of the lambs. There was no skin graded beyond the $4^{\text {th }}$ grade. Out of the 13 lamb skins processed during the $2^{\text {nd }}$ slaughter there wouldn't have been any $4^{\text {th }}$ grade even, if it were not for one of the Menz lambs that was born first and was exposed to lice infestation because the dam was infested with lice. None of the other lambs was infested with any of the ectoparasites, because the dams delivered their lambs after they were treated with diazinon.

Among the lambs slaughtered during the third slaughter, there was no $5^{\text {th }}$ grade or reject at all as compared with the bench mark skins where $50 \%$ of the Menz skins were rejects and $60 \%$ of the Horro skins were in the $5^{\text {th }}$. (Table 5)

The main objective of this trial is to determine the effect of controlling lice and keds by using diazinon to improve the skin quality of sheep skin. Although the effect of the treatment on body wt., carcass wt. and dressing percentage have been taken, these parameters cannot be used to compare between the Menz and the Horro breed adults or their lambs because of the difference of the purchasing date of the two breeds. The Horro sheep were bought seven months after the Menz sheep were bought because of the outbreak of pasteurellosis that occurred in the Menz flock that discouraged the introduction of the Horro sheep before the culmination of the outbreak. The outbreak in the Menz sheep had also caused emaciation and loss of weight which is another factor for the inappropriateness of these parameters to compare the two breeds and their lambs.

Cockle is a disease that can be controlled once the causative agents, the sheep lice Bovicola ovis and the sheep keds Melophagus ovinus are identified and avoided. Heath (1995) mentioned that diazinon with its immediate 'knock down' effect, deal rapidly with lice and in turn cockle disappear relatively quickly. In contrast, the nature of cypermethrin is to spread, from its point of application, within the lipid layer and the stratum corneum of the skin. Depending upon wool length, this procedure can take up to 7 weeks as measured by toxicity to biting lice. 
The scars left due to the allergic reaction would take some time to heal depending on the damages done to the skin and the species of the parasite causing the defect. For example sheep infested with lice only would not have severe skin lesions and scars as do sheep infested with sheep keds alone. The skin of those infested with lice alone heal from the scar faster than the skin infested with sheep keds that have sucking mouth part that pierce and damage the skin of the host and suck blood. The sheep lice do not suck blood. They only feed on the secretion and debris of the sheep skin. That is the reason why the Horro sheep, bred in the mid and lowland regions of the country and have shorter hair than the Menz sheep, are mostly infested by lice and rarely by sheep keds. Sheep keds prefer sheep with long and rough hair. That was the reason why the skin grades of the Horro adult sheep were better than the skin grades of the Menz adult sheep.

The number of lice and keds counted can sometimes be deceptive, because the parasites might die or fall down after inflicting the damage by the allergic reaction of their faeces and saliva for which the hosts are allergic. Heath et al mentioned as small number as 10 lice or keds could cause allergic reaction that resulted in cockle formation on the dermis.(1996)

The treatment with diazinon was recommended every three months to avoid the risk of re-infestation and development of cockle scars. Diazinon has a long residual effect since it stays in the skin for long period of time which causes mortality of the insects that come in contact with the sheep skin treated. Not only does the insecticide treat sheep that is sprayed with the insecticide, it also treats sheep that have not been treated but come in close contact with the treated sheep by contact treatment. That is what happened to the lambs that were suckling their dams that were treated with diazinon in the trial. They were treated by contact and were free of ectoparasites right from their birth. But they were treated after two months of age to avoid any infestation. That was why they had no allergic reaction to the faeces of lice and keds and therefore became free of cockle scars and therefore had better skin quality than their dams $(\mathrm{P}<0.05)$

Sheep pox scars among the Menz sheep created confusion for the skin selectors. As pox scars healed and became smaller in size they looked like scars caused by lice and keds and these caused the Menz sheep skins to be downgraded more than anticipated. 


\section{Acknowledgment:}

The author would like to thank:

- The consortium: USAID-ATEP, Pittards, and DBARC for sponsoring the trial

- EVA for helping in analyzing the data on the skin grades.

- NAHDIC for the diagnosis of the diseases that broke out in the farm and for lending the tattoo pliers for identification of the sheep skins.

- Mr. Reg Hankey and Mr. John Moriarty for the moral support they gave for the continuation of the trial despite the death of over 200 sheep due to the outbreak.

- The Chief of Party of ATEP Mr. Thomas H. Carr and the Deputy Chief of Party Ato Teshome Kebede for their untiring support for the completion of the trial.

- The staff of ATEP and Ethiopia Tannery and DBARC for their full support during the efficacy trial.

\section{References}

Bayou, K. 2009. Cockle is a controllable skin defect. Ethiopian Leather Journal. Vol. 1, No. 3, PP 36-38.

Everett, A.L., Roberts, I.H., Willard, H. J., Apodaca, S.A., Bitcover, E.H., Naghski,J., 1969. The cause of cockle, a seasonal sheepskin defect, identified by infesting a test flock with ked (Melophagus ovinus). J. Am. Leath. Chem. Assoc. 64.460-476.

Heath, A.C.G., Bishop, D.M., Cole, D.J.W., Pfeffer.1996. The development of cockle, a sheep pelt defect, in relation to size of infestation and time of exposure to Bovicola ovis, the sheep-biting louse. Veterinary Parasitology 67, 259-267

Heath, A.C.G., Coles, D.J.W, Bishop, D.M., Pfeffer, A., Cooper,S.M., Risdon,P. 1995. Preliminary investigations in to the aetiology and treatment of cockle, a sheep pelt defect. Veterinary Parasitology 56,239-254.

Ian B. Leach and Bayou K., 1998. Control of sheep and goat skin diseases for improved quality of hides and skins. Proceedings of an In-service training exercise on hides and skins improvement, Food and Agriculture Organization of the United Nations, March 1998 
Sertse, T. Wossene 2007. A study on ectoparasites of sheep and goats in eastern part of Amhara Region, northeast Ethiopia. Small Ruminant Research. ELSEVIER Publication. 69: 62-67

Sertse, T. Wossene, A. 2006. Effect of ectoparasite on quality of pickled skins and their impact on the tanning industries in Amhara Regional State, Ethiopia. Small Ruminant Research. ELSEVIER Publication 69: 55-61.

\section{Annex I}

Procedures followed to produce good quality skins in the flock:

1. The sheep were identified with ear tags as soon as they were bought from the owner recording the address of the origin of the sheep.

2. Before they were purchased they were examined for any livestock disease except for lice and keds infestation.

3. They were sent to quarantine for two weeks before they were taken to DBARC.

4. At the quarantine they were vaccinated against pasteurellosis and sheep pox.

5. A day after their arrival at Debre Birhan Research Centre they were weighed using a weigh bridge and this procedure of taking their body weight continued every month till they were slaughtered.

6. After taking their body weight they were treated with broad spectrum anthelminthics according to their body weight.

7. A week later they were vaccinated against anthrax and peste des petites ruminants (PPR)

8. They were examined for ectoparasites and the lice and keds were recorded

9. They were treated with diazinon by mixing the stock solution at the rate of $1 \mathrm{ml}$ of $60 \%$ solution in $1000 \mathrm{ml}$ of tap water which gave $0.06 \%$ solution.

10. The insecticide was sprayed on each of the sheep, one by one, using knap sack sprayer making sure each sheep was well sprayed with the insecticide.

11. The spraying with the insecticide was repeated two weeks later 
12. One week after the last spray all the sheep were examined for any ectoparasite

13. This procedure was then followed every three months for each of the sheep.

14. Before the flock were sprayed, they were examined to make sure that they were not re-infested with ectoparasites

15. The lambs were sprayed at two months of age, but they all had contact treatment from their dams against ectoparasites.

16. At the end of the trial i.e. on January 16 all the sheep were sent to Luna Export Abattoir to be slaughtered.

17. Before they were slaughtered they were all weighed again.

18. The skin of each sheep was flayed by experienced butchers of Luna Abattoir who made sure there was no flay cuts as much as possible.

19. The skins were then taken to Ethiopia Tannery where the ear tag number of each sheep was transferred on the skin by using a pair of tattoo pliers as seen on the picture above

20. The skins were then preserved using common salt till they were processed in the tannery

21. All the skins were then processed to the pickled stage and graded by experienced skin graders of the Tannery.

22. This procedure resulted in producing the best grade skins in $80-90 \%$ of the lambs although the grades of the adult sheep was not as expected because of the long duration of the infestation with sheep keds in case of the Menz sheep before they were treated.

23. This trial therefore helps us in drawing a lesson that treatment should be extended upto two years and beyond to see the best result in the second generation. 
